\title{
High Performance Liquid Chromatography of Molecular Species from Free Sterols and Sterylglycosides Isolated from Oat Leaves and Seeds ${ }^{1}$
}

\author{
Jürgen Kesselmeier ${ }^{2}$, Waldemar Eichenberger ${ }^{3}$ and Birgit Urban ${ }^{3}$ \\ 3 Botarical Institute, University of Cologne, Gyrhofstraße 15, D- $5000 \mathrm{Koln} 41$, Fed. Rep. Ger. \\ 3 Biochemical Institute, University of Berns, Freie Straße 3, CH - 3012 Berne, Swoitzerland
}

\begin{abstract}
Free sterols and sterylglycosides (SG) from oat leaves and seeds were isolated by conventional thin layer chromatography (TLC) and subjected to high performance liquid chromatography (HPLC) for resolution of molecular species. Acylsterylglycosides, isolated by TLC, were converted to SG by mild alkaline hydrolysis and determined as SG. Sterols and SG were injected onto the column without any chemical treatrnent and the separated species were detected at $200 \mathrm{~nm}$. The separation of SG-species follows exactly the separation of free sterols.

Though gas liquid chromatography still is the method of choice, advantages of HPLC is to analyse directly the SG-specie without hydrolysis and derivatization as compared to GLC. After TLC the sterol- and the SG-fraction are injected directly onto the column. This is extremely important for labile sterylglycosides or sterols, as demonstrated for the avenasterols.
\end{abstract}

Key words: Acybterylglycosides - HPLC - Sterols - Sterylglycosides - Oat (Avena satioa).

Sterols are structural components of the lipid core of cell membranes and are biogenetic precursors of numerous metabolites including plant steroid hormones (Mudd 1980). The importance of SG and ASG as sterol storage forms, as structural components of cell membranes, together with free sterols in intra- or intercellular transport of sterols has been suggested (Eichenberger 1977, Wojciechowski 1980). To answer some of the raised questions, a rapid analysis of small samples is necessary. Many workers have shown that HPLC is applicable to the analysis of free sterols and sterol precursors (cf. Heftmann and Hunter 1979). Their results have given evidence that the use of reversed phase columns is the method of choice for HPLC of free sterols. In most cases the reversed phase column fillings consisted of $\mathrm{C}-18$ coated particles. The eluting solvents often contained higher concentrations of $\mathrm{MeOH}$ or other admixtures, which prevent the detection at the maximum absorption wavelength or lead to a high ground noise (Rees et al. 1976, Kikuchi and Miki 1978, Colin et al. 1979, Thowsen and Schroepfer 1979, Lin et al. 1981). DiBussolo and Nes (1982) used acetonitrile containing 5\% $\mathrm{MeOH}$ on a C-8 column and pure acetonitrile on a $\mathrm{C}-18$ column, thus allowing a more optimal detection at

Abbreviations: SG, sterylglycosides; ASG, acylsterylglycosides; $\mathrm{MeOH}$, methanol; TLC, thin layer chromatography; HPLC, high performance liquid chromatography; GLC, gas liquid chromatography.

- 1 Preliminary reports have been presented on the "4. Arbeitstagung, Pflanzliche Lipide", October 7-8, 1983 in Münster (FRG) and on the "6th International Symposium on the Structure, Function and Metabolism of Plant Lipids", Neuchatel, Switzerland, July 16-20, 1984. 
$205 \mathrm{~nm}$. They showed the influence of various methyl groups, double bonds and branching on the affinity to the column material.

The aim of our work was to develop a HPLC-application not only for free sterols but also for SG and ASG without chemical alteration prior to injection. In order to get a good separation and detection, we used a water-acetonitrile gradient, thus enabling a detection at $200 \mathrm{~nm}$, leading to a high sensitivity, which has been demonstrated for the separation of steroidal saponins (Kesselmeier and Strack 1981). Though GLC still is the method of choice for analyzing free sterols, HPLC is expected to show some advantages as compared to GLC: Derivatization, which often leads to decomposition or structural alteration, and acid hydrolysis, which is necessary for the analysis of SG and ASG by GLC, can be avoided. As shown by Kesselmeier et al. (1984), acid hydrolysis may cause a loss of total sterols up to $80 \%$. Therefore, avoiding acid hydrolysis is extremely important, especially for the detection of some labile SG- and ASG-species, as shown by our experiments.

\section{Materials and Methods}

Extraction and purification of steroids-Seeds and 8 days old oat (Avena sativa L.) primary leaves (3-5 g fr wt; for growth conditions see Kesselmeier and Urban 1983) were extracted by grinding in $\mathrm{MeOH}$ or $\mathrm{CHCl}_{3} / \mathrm{MeOH}=2 / 1(\mathrm{v} / \mathrm{v})$. After centrifugation the pellet was extracted again until all pigments were dissolved. The combined extracts were evaporated and dissolved in $0.5-1.0 \mathrm{ml}$ of $\mathrm{CHCl}_{3} / \mathrm{MeOH}=2 / 1(\mathrm{v} / \mathrm{v})$. Free sterols, SG and ASG were isolated by TLC on precoated silicagel plates, using $\mathrm{CHCl}_{3} / \mathrm{MeOH}=90 / 10(\mathrm{v} / \mathrm{v})$. All solvents were distilled prior to use. For the detection under UV-light $(366 \mathrm{~nm})$ the plates were sprayed with $0.2 \%(\mathrm{w} / \mathrm{v})$ 8-anilino-naphtalene-1-sulfonic acid (Merck, FRG) in MeOH. Spots of free sterols, SG and ASG were scraped off and eluted with $\mathrm{MeOH}$. ASG was converted to SG by mild alkaline hydrolysis: Na-methoxide ( $20 \mu \mathrm{l}$ of a $20 \mathrm{mM}$ solution in $\mathrm{MeOH}$ ) was added to $100 \mu \mathrm{l}$ of ASG extract. The mixture was incubated at $35^{\circ} \mathrm{C}$ for $15 \mathrm{~min}$. SG obtained from ASG was purified by TLC as described above.

High performance liquid chromatography (HPLC)-Free sterols, SG and SG obtained from ASG were dissolved in $300-500 \mu \mathrm{l} \mathrm{MeOH}$. Via a Rheodyne valve $20 \mu \mathrm{l}$ of this solution were directly injected onto the HPLC-column (Reversed phase; Spherisorb Hexyl, $5 \mu \mathrm{m}$; $125 \times 4.6 \mathrm{~mm}$; Bischoff, FRG). Separation was accomplished by a 30 min-gradient elution from $50 \%$ to $100 \%$ acetonitrile (Baker, HPLC-grade) in water. The flow rate was $1 \mathrm{ml} \mathrm{min}-1$. Detection was achieved at $200 \mathrm{~nm}$. The HPLC system and the detector (Uvikon 720) were products of Kontron (Switzerland). Peaks were identified by cochromatography with commercial compounds and by GLC-MS of collected peaks according to Eichenberger and Urban (1984). Calibration was obtained with commercial cholesterol and stigmasterol.

Digestion of $S G$ and $A S G$ for GLC-analysis-Sterols were released from SG and ASG by acid hydrolysis according to Eichenberger (1982). Additionally, SG was converted to the corresponding free sterols by enzymatic digestion: $0.5 \mathrm{mg}$ SG was dissolved in $30 \mu \mathrm{l}$ dimethylsulfoxide. After adding $0.5 \mathrm{ml}$ citrate buffer $(0.1 \mathrm{~m} ; \mathrm{pH} 5.0$ ), containing $10 \mathrm{mg} \beta$-glucosidase (Calbiochem; EC 3.2.1.21) the mixture was incubated for $15 \mathrm{~h}$ at $32^{\circ} \mathrm{C}$ under shaking. Released sterols were extracted with petroleum ether $\left(40-50^{\circ} \mathrm{C}\right) /$ diethylether $=1 / 1(\mathrm{v} / \mathrm{v})$.

GLC-MS analysis of sterols-For details see Eichenberger and Urban (1984).

\section{Results and Discussion}

Separation-Fig. 1 and 2 show the HPLC separation of free sterols obtained from oat leaves and seeds as compared to GLC separation. Each HPLC-Peak was identified by GLC-MS- 

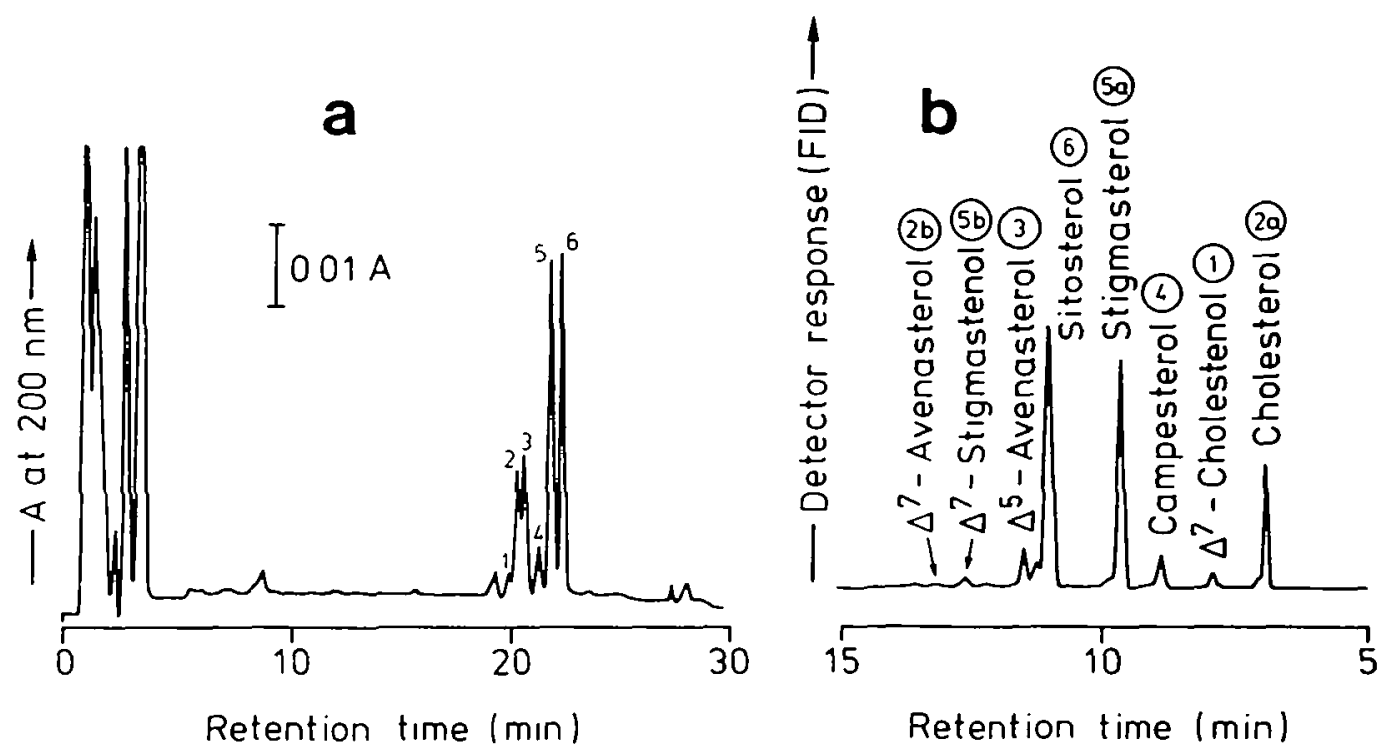

Fig. 1 a) HPLC- and b) GLC-separation of free sterols from oat leaves. Identification of HPLC-peaks was obtained by GLC-MS-analysis of collected single peaks (see Fig. 5). For denomination of HPLC-Peaks see corresponding numbers in the GLC-chromatogram. HPLC-quantities (nmol/peak): $1=0.25 ; 2=1.14 ; 3=0.97$; $4=0.49 ; 5=2.01 ; 6=2.80$.

analysis after collection (Fig. 5). The elution sequence is in accordance with DiBussolo and Nes (1982). Striking differences concerning the avenasterols and stigmasterol are seen comparing free sterols from oat leaves with those from oat seeds. The main components in leaf extracts are sitosterol and stigmasterol, whereas seeds contain mainly $\Delta^{5}$-avenasterol and sitosterol. These HPLC-results are confirmed by GLC-analysis (Fig. $1 \mathrm{~b}$ and $2 \mathrm{~b}$ ) and are in accordance with Knights (1965) and Knights and Laurie (1967). HPLC-separation of free sterols shows coelution of $\Delta^{7}$-avenasterol/cholesterol and $\Delta^{7}$-stigmastenol/stigmasterol, thus confirming that GLC still is the method of choice for the analysis of free sterols. However, for HPLC-analysis there is no need for derivatization, which often leads to decomposition or structural alteration. Thus, HPLC offers a method to analyse rapidly samples with smaller amounts of sterols.

The aim of our work was to develop a sensitive HPLC-application not only for free sterols but also for SG and ASG because to our knowledge no attempt has been made for separating intact SG and ASG. ASG-species, however, contain fatty acids, which influence its adsorption due to the sterol backbone (Kesselmeier et al. 1984). Moreover, unsaturated fatty acids influence the absorption at $200 \mathrm{~nm}$ and prevent a reliable quantitation of ASG-species. Therefore, ASG was converted to SG by mild alkaline hydrolysis. As shown in Fig. 3 the elution sequence of intact SG-species follows exactly that of free sterols, thus showing that the glycosidic residue has no influence on the HPLC-separation except the elution velocity. The HPLC-separation of intact SG-species clearly illustrates the main advantage of HPLC; no acid hydrolysis and no derivatization is necessary for the rapid analysis of SG. This is extremely important for labile $\mathrm{SG}$-species, in our case the $\Delta^{7}$ - and $\Delta^{5}$-avenasterolglycosides. Acid hydrolysis and derivatization for GLC-analysis totally decompose these species, thereby causing a composition, which is no longer identical with the one in vivo (Fig. 8). Both species were detected by GLC, when the sterols were released from the SG-fraction by enzymatic digestion (Fig. 4). However, en- 

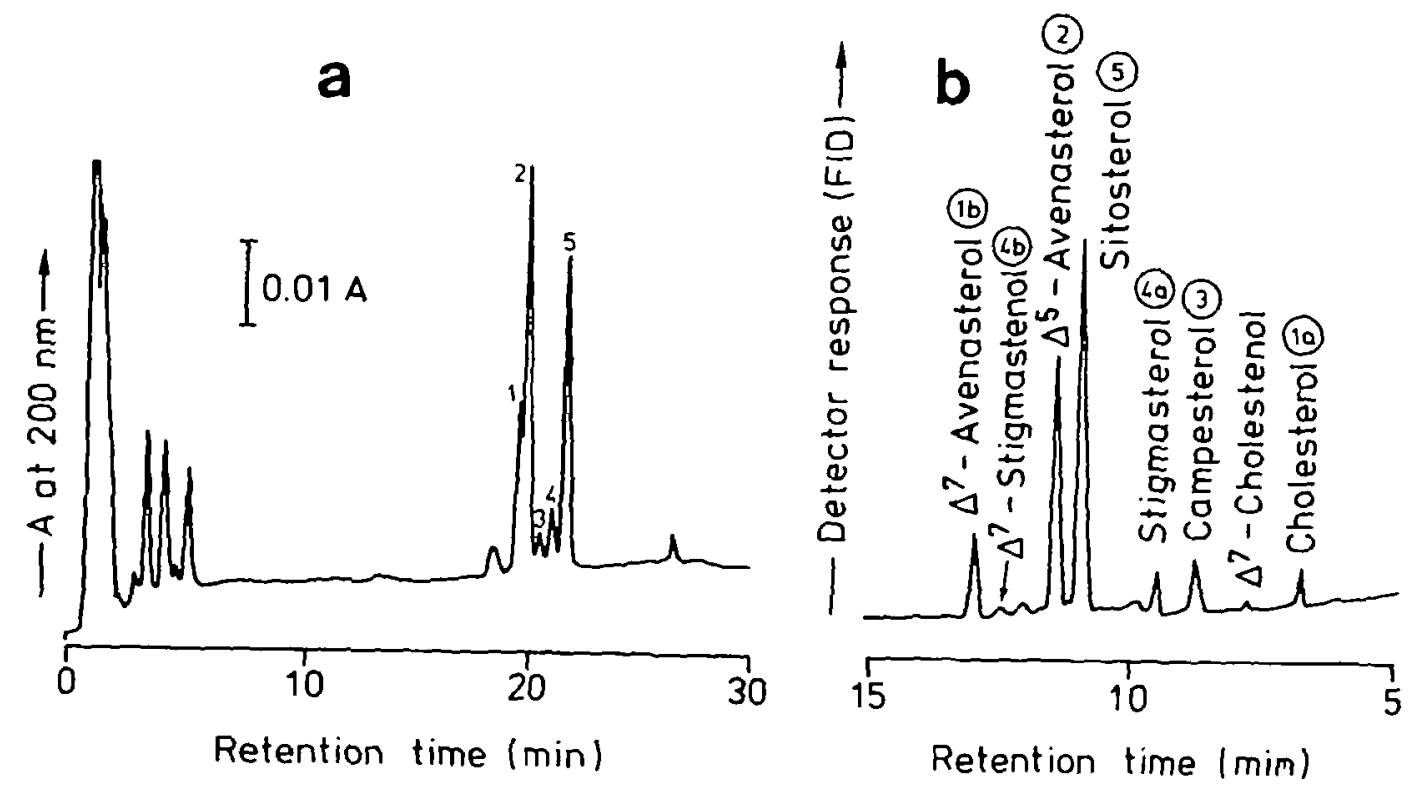

Fig. 2 a) HPLC- and b) GLC-separation of free sterols from oat seeds. For identification and denomination see legend to Fig. 1. HPLC-quantities (nmol/peak): $1=1.22 ; 2=2.61 ; 3 \sqcap 0.35 ; 4=0.37 ; 5 \rightleftharpoons 2.65$.

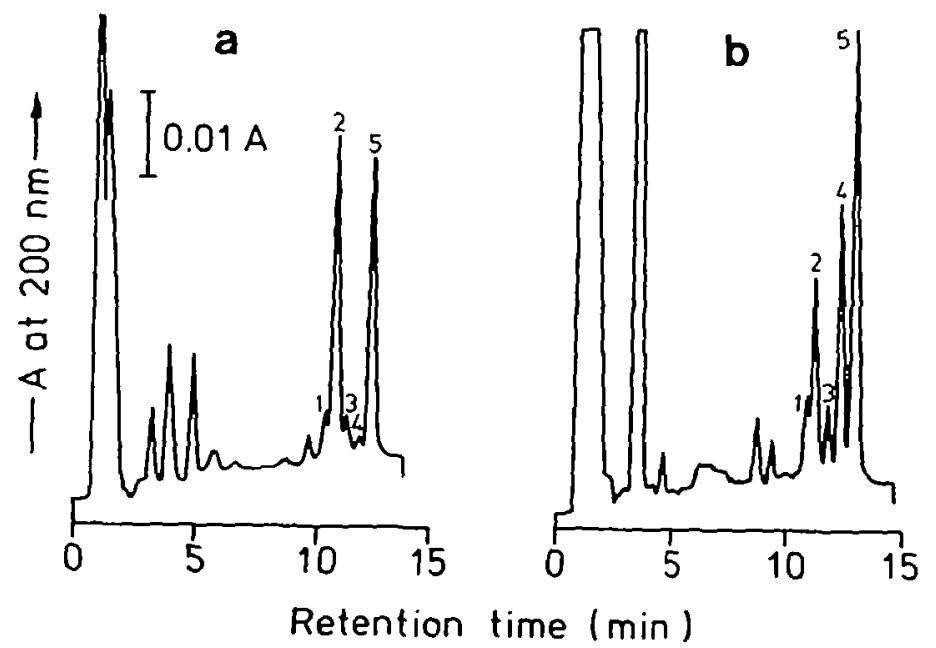

Fig. 3 HPLC-separation of intact sterylglycosides from oat seods (a) and leaves (b).

\begin{tabular}{clcc}
\hline Peak-No. & Compound & \multicolumn{2}{c}{ nmol/peak in } \\
\hline 1 & Cholesterol- $+\Delta^{7}$-Avenasterolglycoside & 0.54 & $\mathrm{~b}$ \\
2 & $\Delta^{5}$-Avenasterolglycoside & 3.24 & 0.68 \\
3 & Campesterolglycoside & 0.46 & 1.00 \\
4 & Stigmasterol- and $\Delta^{7}$-Stigmastenolglycoside & 0.20 & 0.58 \\
5 & Sitosterolglycoside & 2.70 & 1.50 \\
\hline
\end{tabular}



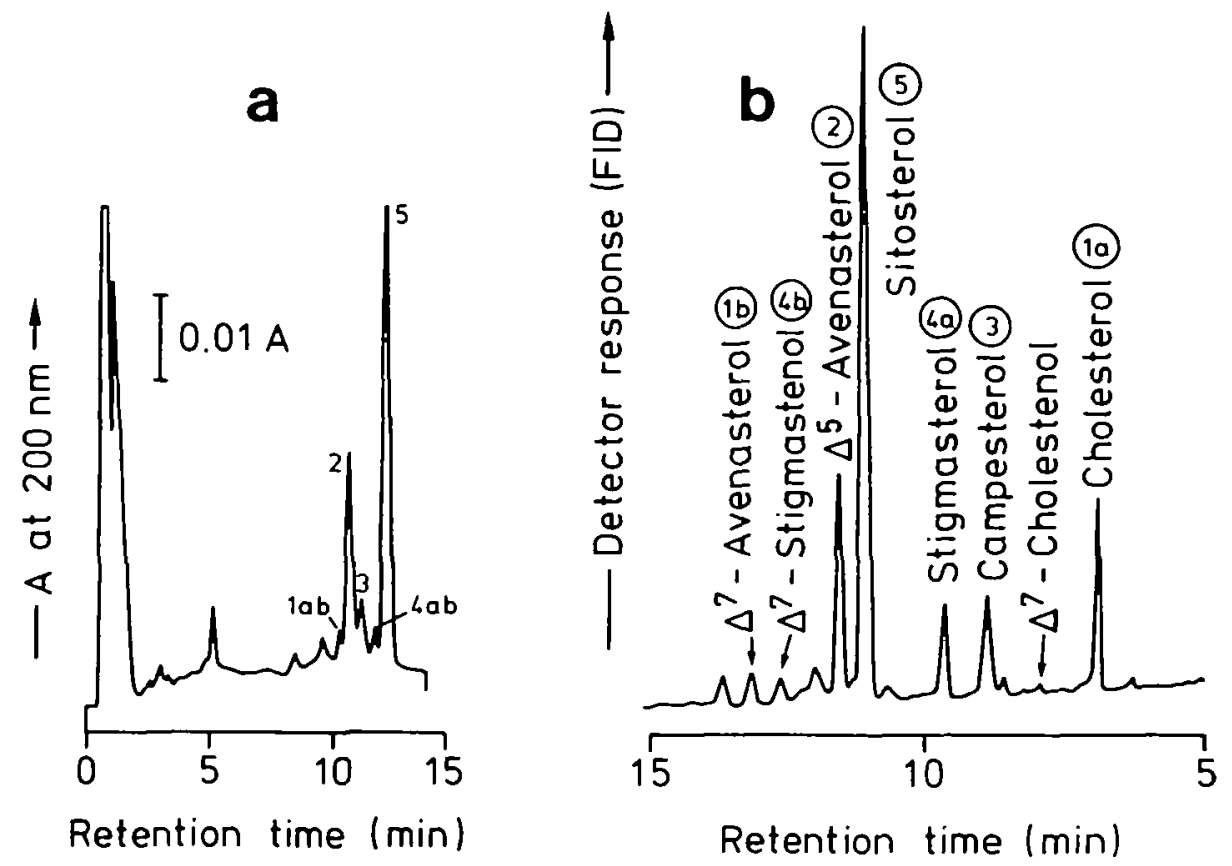

Fig. 4 Comparison of GLC-analysis (a) of sterols obtained from sterylglycosides (SG) by enzymatic degradation with the corresponding HPLC-analysis (b) of intact SG from oat flour. For denomination see corresponding numbers in the GLC-chromatogram. Oat flour was a generous gift of the Kentaur AG (Lützelflüh, Switzerland) and was extracted in the same way as intact seeds.

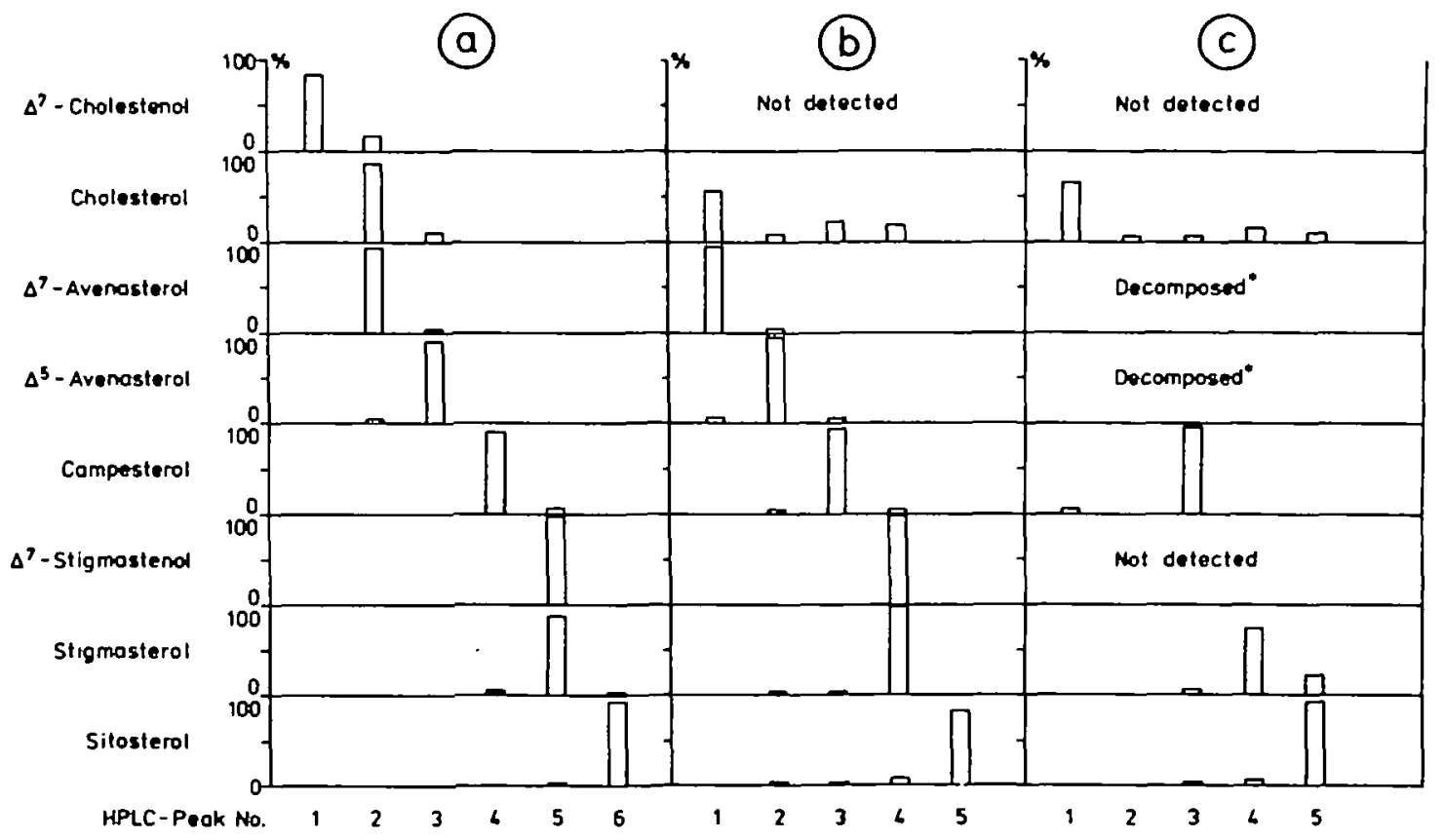

Fig. 5 Distribution of sterols on HPLC-peaks analysed after collection of individual peaks by GLC. Sterols were released from SG by acid hydrolysis, thus leading to a decomposition of both avenasterols (see Fig. 3-4). a) Free sterols from oat leaves, b) Free sterols from oat seeds, c) Sterylglycosides from oat leaves. 


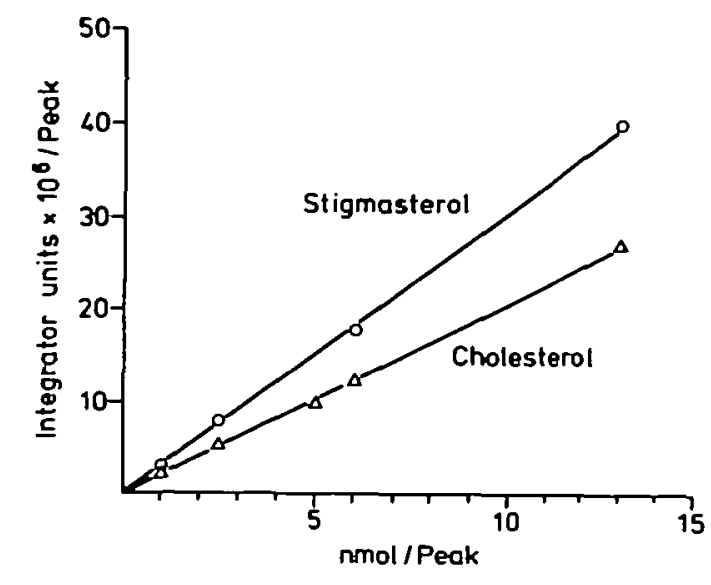

Fig. 6 Calibration curves, depending on the number of double bonds per molecule (Averages of 4 HPLCmeasurements $\pm 2 \%$ ).

zymatic digestion causes other problems as for example enzyme specifity or SG-solubility in aqueous solution.

The identification of free sterols and intact SG-species was achieved by collecting each peak and analyzing it by GLC-MS (Fig. 5). Oat free sterols and, in identical elution sequence, the intact SG-species were eluted in 5 or 6 HPLC-peaks, depending whether $\Delta^{7}$-cholestenol(glycoside) appears or not.

Quantitation-The detection of the underivatized sterol- and SG-species at $200 \mathrm{~nm}$ depends on the number of double bonds per molecule, as it has also been shown for the separation and quantitation of molecular species of plant glyco- and phospholipids (Kesselmeier and Heinz 1984). Using cholesterol (one double bond) and stigmasterol (two double bonds) detectability was in the range of $0.2 \mathrm{nmol}(0.08 \mu \mathrm{g})$ and linearity was found up to $13 \mathrm{nmol}(5.2 \mu \mathrm{g})$ tested (Fig. 6). Stigmasterol showed a 1.5 fold higher absorption at $200 \mathrm{~nm}$ as compared to cholesterol,

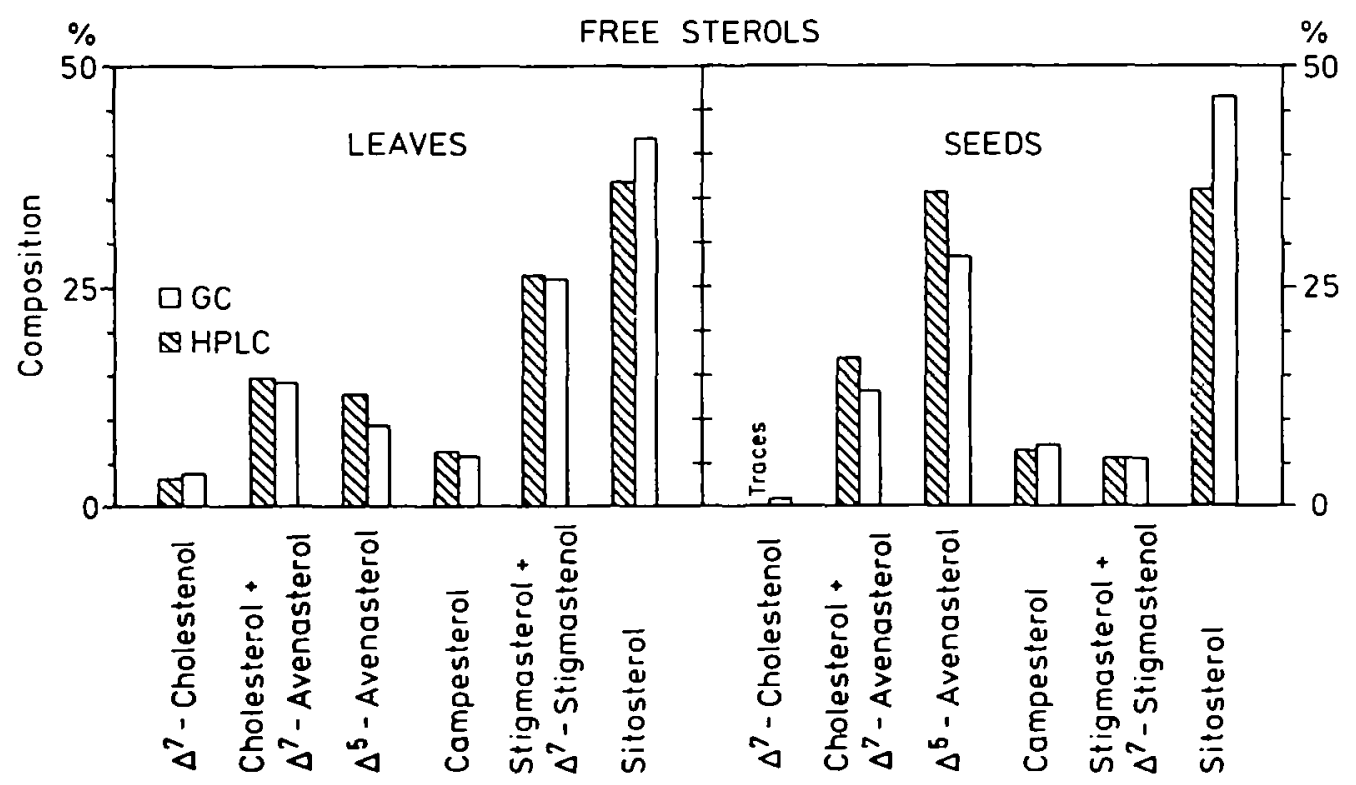

Fig. 7 Comparison of GLC-analysis with the corresponding HPLC-analysis of free sterols from oat leaves and seeds. Composition on a molar basis $(\%)$. 


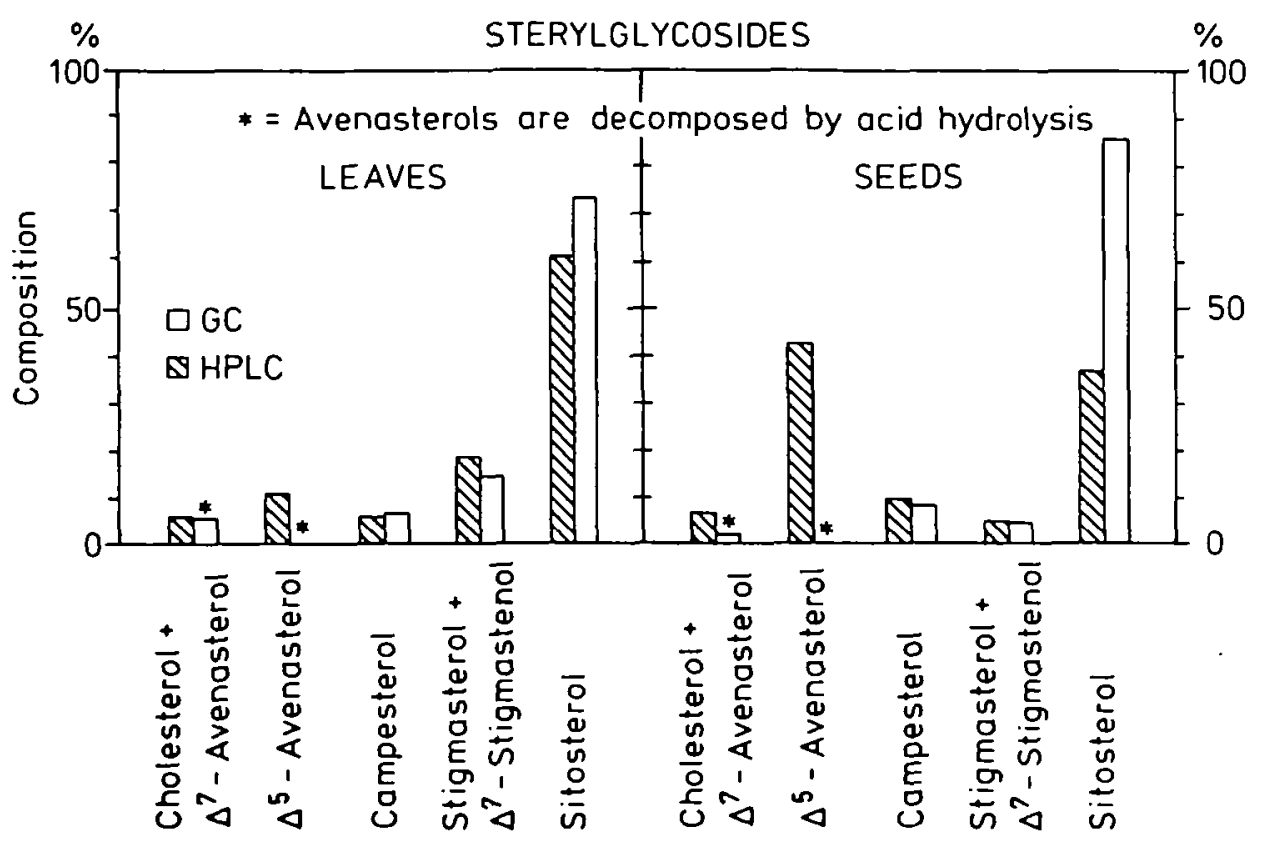

Fig. 8 Comparison of GLC-analysis of sterols obtained from sterylglycosides by acid hydrolysis with the corresponding HPLC-analysis of intact SG from oat leaves and seeds. Decomposition of avenasterols is avoided by enzymatic digestion (see Fig. 9). Composition on a molar basis (\%).

due to the number of double bonds. The peak area per nmol cholesterol was identical to that found for steroidal saponins with one double bond (Kesselmeier and Strack 1981), thus showing that glycosidic residues do not affect the detection at $200 \mathrm{~nm}$. Therefore, nmol/peak-area-ratios of free sterols may also be used for calculating SG-species.

Fig. 9 Comparison of GLC-analysis of sterols obtained from sterylglycosides (SG) by enzymatic digestion' with the corresponding HPLCanalysis of intact SG from oat flour (Oat flour was a generous gift of the Kentaur AG, Lützelfüh, Switzerland, and was extracted in the same way as intact seed). Composition on a molar basis (\%).

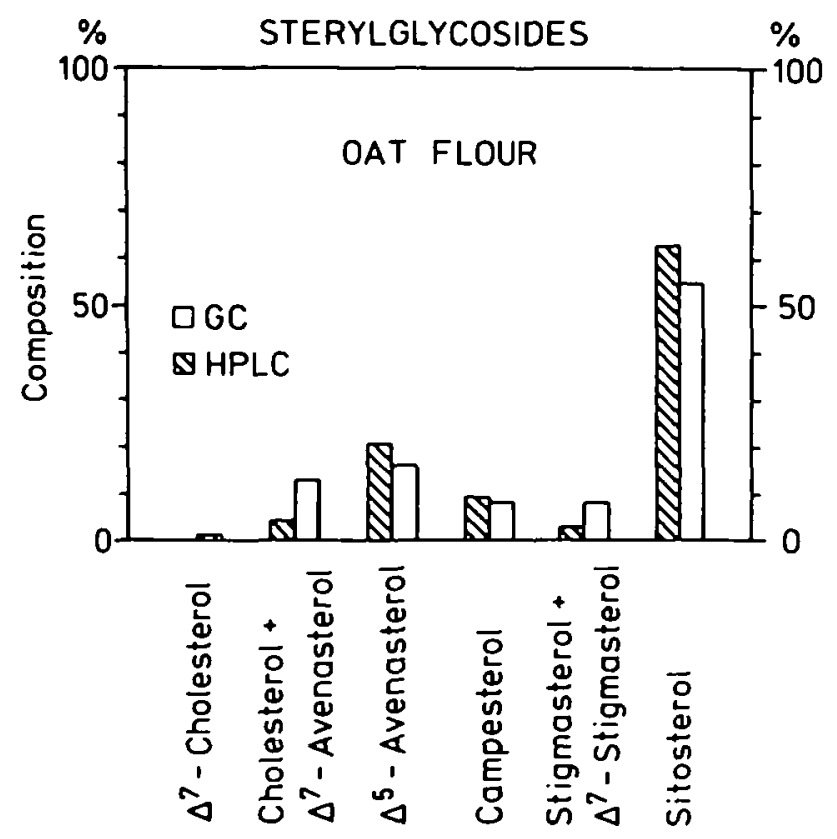


Quantitative comparison of $G L C$ - and HPLC-analysis-Using the calibration described above, we compared the species composition of free sterols and SG from oat leaves and seeds (Fig. 7-9). Within the limitations caused by HPLC-separation and GLC depending difficulties, a good agreement between both methods was found, thus showing the possibility of analyzing free sterols and especially intact SG by HPLC without any chemical alteration of the molecular structures. The sensitivity of HPLC at $200 \mathrm{~nm}$ is similar or even better than that of a GLCmethod, especially because no hydrolysis and derivatization is necessary. Therefore, an analysis of small samples with a low steroid content is possible. During our investigations we found that an extract equivalent to $1 \mathrm{~g}$ fr wt of leaves is sufficient for 5 HPLC analyses. The main limitation is the range of detectability on the TLC plate. Due to the minimal loss of steroids after TLCpurification the HPLC-application for free sterols, SG and SG from ASG offers a method to analyse the function of these steroids as structural components and their intra- or intercellular transport starting from small amounts of isolated cell membranes or other cell fractions.

This work was supported by the Deutsche Forschungsgemeinschaft. The skilful assistance of Mrs. Ute Laudenbach is gratefully acknowledged.

\section{References}

Colin, H., G. Guichon and A. Siouffi (1979) Comparison of various sytems for the separation of free sterols by high performance liquid chromatography. Anal. Chem. 51:1661-1666.

DiBussolo, J. M. and W. R. Nes (1982) Structural elucidation of sterols by reversed phase liquid chromatography: I. Assignment of retention coefficients to various groups. J. Chrom. Sii. 20: 193-202.

Eichenberger, W. (1977) Steryl glycosides and acylated steryl glycosides. In Lipids and Lipid Polymers in Higher Plants. Edited by M. Tevini and H. K. Lichtenthaler. pp. 169-182. Springer Verlag, Berlin.

Eichenberger, W. and B. Urban (1984) Sterols in seeds and leaves of oat (Aunna sativa L.) Plant Cell Rep. 3: 226-229.

Eichenberger, W. (1982) Incorporation of 4-14C cholesterol into steryl derivatives and saponins of oat (Avena sativa L.) plants. Plant Cell Rep. 1: 253-256.

Heftmann, E. and I. Hunter (1979) High pressure liquid chromatography of steroids. J. Chrom. 165: 283299.

Kesselmeier, J. and D. Strack (1981) High performance liquid chromatographic analysis of steroidal saponins from Avena sativa L. Z. Naturforsch. 36c: 1072-1074.

Kesselmeier, J. and B. Urban (1983) Subcellular localization of saponins in green and etiolated leaves and green protoplasts of oat (Avena saliva L.). Proloplasma 114: 133-140.

Kesselmeier, J., W. Eichenberger and B. Urban (1984) Application of high performance liquid chromatography to analysis of free sterols, sterylglycosides and acylsterylglycosides. In Structure, Function and Metabolism of Plant Lipids. Edited by P. A. Siegenthaler and W. Eichenberger. pp. 233-236. Elsevier Science Publishers BV, Amsterdam, Netherlands.

Kesselmeier, J. and E. Heinz (1985) Separation and quantitation of molecular species from plant lipids by high performance liquid chromatography. Anal. Biochem. 144: 319-328.

Kikuchi, N. and T. Miki (1978) The separation of date (Phoenix dactylifera) sterols by liquid chromatography. Mikrochim. Acta 1 : 89-96.

Knights, B. A. (1965) Identification of the sterols of oat seed. Phplochemistry 4: 857-862.

Knights, B. A. and W. Laurie (1967) Application of combined gas-liquid chromatography-mass spectrometry to the identification of sterols in oat seed. Phytochemistry 6: 407-416.

Lin, J. T., W. D. Nes and E. Heftmann (1981) High performance liquid chromatography of triterpenoids. $J$. Chrom. 207: 457-463.

Mudd, J. B. (1980) Sterol interconversions. In The Biochemistry of Plants. Vol. 4. Edited by P. K. Stumpf. pp. 509-534. Academic Press, New York.

Rees, H. H., P. L. Donnahey and T. W. Goodwin (1976) Separation of $\mathrm{C}_{27}, \mathrm{C}_{28}$ and $\mathrm{C}_{29}$ sterols by reversed phase high performance liquid chromatography on small particles. J. Chrom. 116: 281-291. 
Thowsen, J. R. and G. J. Schroepfer (1979) Sterol synthesis. High pressure liquid chromatography of $\mathrm{C}_{27}$ sterol precursors of choletererol. J. Lipid Res. 20: 681-685.

Wojciechowski, Z. A. (1980) Biosynthesis of sterol conjugates in plants. In Biogenesis and Functions of Plant Lipids. Edited by P. Mazliak, P. Beneviste, C. Costea and R. Douce. pp. 405-415. Elsevier/North Holland, Amsterdam, Netherlands.

(Received November 12, 1984; Accepted January 14, 1985) 